\title{
Многообразие свойств приборных структур на основе нитридов элементов III группы, связанное с модификацией фрактально-перколяционной системы
}

\author{
(C) В.В. Емцев ${ }^{1}$, Е.В. Гущина ${ }^{1}$, В.Н. Петров ${ }^{1}$, Н.А. Тальнишних ${ }^{2}$, А.Е. Черняков ${ }^{2}$, Е.И. Шабунина ${ }^{1}$, \\ Н.М. Шмидт ${ }^{1, \uparrow, ~ А . С . ~ У с и к о в ~}{ }^{3}$, А.П. Карташова ${ }^{1}$, А.А. Зыбин ${ }^{4}$, В.В. Козловский ${ }^{5}$, \\ М.Ф. Кудояров ${ }^{1}$, А.В. Сахаров ${ }^{1}$, Г.А. Оганесян ${ }^{1}$, Д.С. Полоскин ${ }^{1}$, В.В. Лундин ${ }^{1}$ \\ ${ }^{1}$ Физико-технический институт им. А.Ф. Иоффе Российской академии наук, \\ 194021 Санкт-Петербург, Россия \\ ${ }^{2}$ НТЦ микроэлектроники Российской академии наук, \\ 194021 Санкт-Петербург, Россия \\ ${ }^{3}$ Nitride Crystals Inc., 181 E Industry Ct., Ste. B, Deer Park, \\ NY 11729, USA \\ 4 ЗАО „Светлана-Электронприбор“, \\ 194156 Санкт-Петербург, Россия \\ ${ }^{5}$ Санкт-Петербургский политехнический университет Петра Великого, \\ 195251 Санкт-Петербург, Россия \\ ฯ E-mail: Natalia.Shmidt@mail.ioffe.ru
}

(Получена 21 декабря 2017 г. Принята к печати 25 декабря 2017 г.)

\begin{abstract}
Фрактально-перколяционная система, включающая протяженные дефекты и случайные флуктуации состава твердого раствора, формируется в процессе роста приборных структур на основе нитридов элементов III группы. Установлено, что свойства этой системы определяются не только условиями роста. Показано, что многообразие электрических и оптических свойств светодиодов $\mathrm{InGaN} / \mathrm{GaN}$, излучающих на длинах волн 450-460 и 519-530нм, а также электрофизических свойств HEMT-структур AlGaN/GaN вызвано модификацией свойств фрактально-перколяционной системы как в процессе роста, так и под действием инжекционного тока и радиационных воздействий. Обсуждается влияние этих особенностей на срок службы светоизлучающих приборов и надежность НЕМТ-структур AlGaN/GaN.
\end{abstract}

DOI: 10.21883/FTP.2018.07.46056.8805

\section{1. Введение}

Полупроводниковые материалы на основе нитридов элементов III группы широко используются в светоизлучающих диодах (LED) видимого и ультафиолетового диапазона, в лазерных диодах, а также в других оптических и электронных приборах, таких как силовые диоды Шоттки и транзисторы с большой подвижностью носителей заряда. Наибольшие успехи по реализации потенциальных возможностей этих материалов достигнуты в создании высокоэффективных синих светодиодов на основе квантово-размерных структур InGaN/GaN на длину волны излучения 450-460 нм [1]. Подобный успех пока не удается реализовать для светоизлучающих приборов в зеленой и ультрафиолетовой областях спектра [2]. Эти светодиоды в несколько раз уступают синим светодиодам по эффективности и сроку службы $[2,3]$.

Индустрия AlGaN/GaN-HEMT (high electron mobility transistor) с двумерным каналом успешно развивается, и с каждым годом растут выходные мощности и рабочие частоты. Однако проблема низкой надежности параметров этих приборов, вызванная увеличением тока утечки затвора, падением выходной мощности и частоты при эксплуатации, в полной мере не решена до сих пор, несмотря на многолетние усилия мирового научного сообщества $[4,5]$.
Следует отметить, что для светодиодов, в том числе излучающих в синей области спектра, проблема снижения мощности с увеличением плотности тока $>10 \mathrm{~A} / \mathrm{cm}^{2}$ и волнообразного течения деградации внешней квантовой эффективности в первые 2000 ч также не решена [6].

Представляется, что эти проблемы во многом связаны с фундаментальными свойствами этих материалов, обусловленными их фрактальной природой, характером организации наноматериала [7]. Наноструктурная организация материала в III-N-структурах проявляется в виде нарушения слоевого механизма роста, существования областей с двумерным и трехмерным характером роста в одной и той же приборной структуре, случайных флуктуаций состава твердых растворов III-N и неоднородной релаксации внутренних механических напряжений, проявляющейся не только в изгибе всей структуры, но и в локальных областях через систему протяженных дефектов и случайные неоднородности состава. Все эти особенности встроены в квантово-размерную активную область (multi quantum well, MQW) приборных структур и порождают многообразие форм организации приборных структур. Кроме того, протяженные дефекты и случайные флуктуации состава твердого раствора являются основой для образования фрактально-перколяционной системы (ФПС). Существование ФПС проявляется в особенностях вольт-амперных характеристик (BAX) приборных структур, наблюдавшихся в многочисленных 
работах [7-9]. В работах приводятся такие особенности ВАХ светодиодов, как значения фактора идеальности $n>2$ при малых смещениях, присутствие нелинейных шунтов, изменяющих проводимость на порядки вследствие изменения характера организации наноматериала $[7,10]$. Один из возможных механизмов, обеспечивающий проводимость этой системы, - туннелирование носителей заряда, вызванное передачей энергии при электрон-фононном взаимодействии [11], другой связан с присутствием близко расположенных донорноакцепторных центров [12]. Существование ФПС является общей особенностью наноматериалов на основе нитридов элементов III группы. Ранее было показано [7], что характер организации наноматериала нитридов элементов III группы можно количественно охарактеризовать мультифрактальным параметром степени упорядоченности $\left(\Delta_{p}\right)$. Этот параметр отражает степень нарушения локальной симметрии внутренних связей самоподобных фракталов в целое и используется в современном материаловедении для характеризации материалов со сложной внутренней структурой. Для синих светодиодов, а также светодиодов на длину волны 368 нм, полученных из структур, классифицированных количественно по значению этого параметра, была выявлена корреляция уровня проводимости нелинейных шунтов и искажений прямой ветви ВАХ при малых смещениях, а также срока службы светодиодов с величиной этого параметpa $[13,14]$. Увеличение параметра $\Delta_{p}$, как было показано в [7], сопровождается увеличением областей трехмерного роста, увеличением неоднородного распределения дислокаций в структуре, образованием скоплений дислокаций, увеличением на порядки проводимости нелинейных шунтов. При исследовании AlGaN/GaN-HEMT также были получены первые обнадеживающие результаты по корреляции подвижности носителей заряда в двумерном канале со значениями параметра $\Delta_{p}[15]$. Следует отметить, что свойства ФПС и их влияние на эффективность и срок службы зеленых светодиодов, так же как и на надежность НЕМТ-структур, мало исследованы.

Целью работы являлось изучение многообразия электрических и оптических свойств светодиодов $\mathrm{InGaN} / \mathrm{GaN}$, излучающих на длинах волн 450-460, 519-530нм, а также электрофизических свойств HEMT-структур AlGaN/GaN, вызванного модификацией свойств фрактально-перколяционной системы как в процессе роста, так и под действием инжекционного тока и радиационных воздействий.

\section{2. Методы и объекты исследования}

Эксперименты проводились на HEMT-структурах AlGaN/GaN, выращенных методом MOCVD (metalloorganic chemical vapor deposition), конструктивные и технологические подробности приведены в [16]. Для исследований были выбраны три типа НЕМТ-структур, существенно различающихся только по характеру организации наноматериала, количественно охарактеризованные мультифрактальным параметром $\Delta_{p}: 0.345,0.350,0.357$. Из структур каждого типа были изготовлены образцы с омическими контактами для измерения подвижности электронов в двумерном канале методом Ван-дер-Пау, а также транзисторы в $3 \mathrm{AO}$ „Светлана-Электронприбор“ с топологией, приведенной в [16]. Облучение проводилось протонами, ускоренными на циклотроне ФТИ им. А.Ф. Иоффе до энергии 1.0 МэВ, в вакууме при остаточном давлении $10^{-5}$ Торр. Три типа образцов НЕМТструктур и небольшие партии транзисторов из этих же структур, облучались протонами с дозами $5 \cdot 10^{13}$, $1 \cdot 10^{14}, 2 \cdot 10^{14} \mathrm{~cm}^{-3}$. Морфология поверхности структур до и после облучения изучалась методом атомносиловой микроскопии (АСМ), количественно оценивался общепринятый параметр оценки шероховатости поверхности RMS, максимальные отклонения величины шероховатости Peak-to-peak $\left(P_{p}\right)$, а также значения $\Delta_{p}$. Точность определения мультифрактального параметра \pm 0.002 оценивалась по нескольким полям сканирования. Этот параметр рассчитывается методами мультифрактального анализа путем обработки массива данных, получаемых в атомно-силовом микроскопе при сканировании поверхности слоев и приборных структур [7]. Кроме того, исследовались ВАХ затворов собранных транзисторов после каждой дозы облучения.

Светодиоды на основе структур InGaN/GaN с разным содержанием индия, излучающие на длинах волн 450-460, 519-530 нм, были выращены методом MOCVD на сапфировых подложках. Основные результаты были получены на коммерческих светодиодах со светоизлучающей площадью $950 \times 950$ мкм. Светодиоды из нескольких партий с разной длиной волны излучения имели следующие значения внешней квантовой эффективности (ВКЭ) $\eta$ : 45-60\% (450-460 нм), 20\% (519 нм), $30 \%$ ( 530 нм, партия I), 12-14\% (530 нм, партия II). Для коммерческих светодиодов оценка свойств ФПС опиралась на ранее установленную корреляцию проводимости каналов, локализованных в протяженных дефектах, со значениями $\Delta_{p}$ и величиной токов при смещениях $<1.5 \mathrm{~B}$, а также корреляцию искажений прямой ветви BAX при смещениях $<2$ В, отражающую присутствие локальных областей малой площади с пониженными барьерами, часто вызванными присутствием неравновесных твердых растворов, обогащенных индием [7].

Эксперименты по старению светодиодов проводились при плотности тока $65 \mathrm{~A} / \mathrm{cm}^{2}$ и температуре $p-n$-перехода $110^{\circ} \mathrm{C}$. Большая часть исследований проводилась после финальной стадии деградации, когда величина ВКЭ светодиодов в максимуме уменьшалась на 30\% относительно значений до старения. На этой стадии исследовались изменения ВАХ, зависимостей ВКЭ от плотности тока (или тока) по сравнению с этими же характеристиками и зависимостями до старения. Кроме того, применялись методы исследования низкочастотного шума, которые, как известно, позволяют получить интегральную информацию не только о точечных дефектах, но и о флуктуациях зарядов, высоты барьеров, о степени однородности протекания тока, о присутствии областей локального перегрева [17]. Исследование особенностей низкочастотного шума проводилось в диапазоне частот 
1-100 000 Гц. Спектральная плотность шума измерялась при плотностях тока $10^{-6}-50 \mathrm{~A} / \mathrm{cm}^{2}$ и температурах 300 , $77 \mathrm{~K}$ для всех светодиодов.

\section{3. Экспериментальные результаты и их обсуждение}

\section{1. Влияние на оптические} и электрические свойства светодиодов, излучающих в спектральном диапазоне 519-530 нм, модификации фрактально-перколяционной системы в процессе роста и под действием инжекционного тока при тестировании на срок службы

Исследование светодиодов, полученных из структур зеленого свечения с разными значениями параметра $\Delta_{p}$, подтвердило ранее выявленную для синих светодиодов корреляцию $\mathrm{BAX}$ при малых смещениях со значениями параметра $\Delta_{p}$, а также пороговую зависимость значений ВКЭ от уровня проводимости шунтирующих каналов, приводящих к снижению ВКЭ более, чем на $30 \%$, при значениях $\Delta_{p}>0.345$, уровню тока $>10^{-8} \mathrm{~A}$ при смещении $1.5 \mathrm{~B}$, а также сдвигу максимума зависимости ВКЭ от плотности тока в область больших плотностей тока. Кроме того, для части зеленых светодиодов с низким уровнем проводимости шунтов и $\Delta_{p}<0.345$ выявлены сдвиг максимума ВКЭ в сторону больших плотностей тока и низкие значения ВКЭ, обычно наблюдаемые на светодиодах с худшей упорядоченностью. Зеленые светодиоды с длиной волны максимума интенсивности в спектре излучения 519-530 нм с такими же особенностями были выявлены среди коммерческих зеленых светодиодов. Для выяснения причин низких значений ВКЭ и наблюдаемых особенностей были сформированы партии зеленых коммерческих светодиодов с длиной волны в максимуме интенсивности спектра излучения 530 нм с ВКЭ $30 \%$ (партия I) и 12-14\% (партия II), а также с длиной волны 519 нм и ВКЭ $19-20 \%$, собранных по одной из общепринятых в коммерческих компаниях технологии. Синие светодиоды из тех же компаний, с такой же сборкой, с длиной волны излучения 454 нм и ВКЭ на этой длине волны $57-60 \%$ были использованы в качестве контрольной партии. При этом светодиоды всех партий имели близкий уровень проводимости шунтов при смещениях $<2 \mathrm{~B}$, соответствующий высокой степени упорядоченности наноматериала, $\Delta_{p}<0.345$. Кроме того, все светодиоды имели одинаковую геометрию слоев активной области (MQW), содержащей по 5 пар ям $\mathrm{InGaN}$ и барьеров $\mathrm{GaN}$, с толщинами слоев соответственно 3 и 10 нм, которая контролировалась по виду профиля распределения носителей заряда в ямах и барьерах. Профиль распределения практически совпадал для всех светодиодов, кроме партии I. Для этой партии только 1-я яма оказалась в области объемного заряда при нулевом смещении, что привело к более сильному падению ВКЭ, чем на других светодиодах, при плотностях тока $>50 \mathrm{~A} / \mathrm{cm}^{2}$, но к падению эффектив-

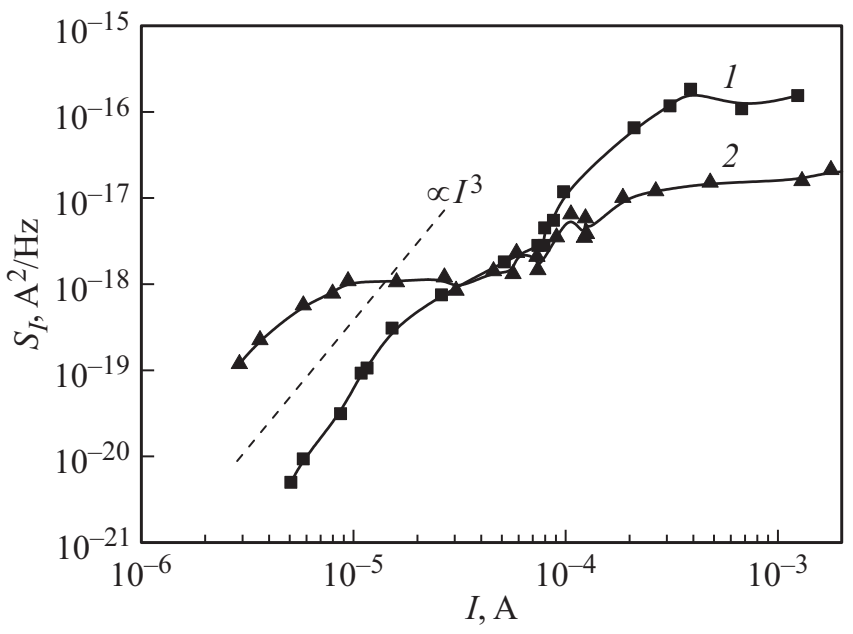

Рис. 1. Зависимости спектральной плотности шума от тока зеленых светодиодов, излучающих на длине волны 530 нм, при температурах 77 (1) и $300 \mathrm{~K}(2)$.

ности на 30\% при меньших плотностях. Присутствие ФПС в зеленых и синих светодиодах [7] выявляется по особенностям зависимостей спектральной плотности токового низкочастотного шума от тока при 77 и $300 \mathrm{~K}$ (рис 1). Появление характерного участка совпадения зависимостей спектральной плотности токового низкочастотного шума $\left(S_{I}\right)$ от тока, вида $S_{I} \propto I$, в диапазоне токов $3 \cdot 10^{-5}-10^{-4} \mathrm{~A} / \mathrm{cm}^{2}$ при температурах 300 и $77 \mathrm{~K}$, согласно [18], свидетельствует о латеральном туннелировании носителей заряда, идентифицированном ранее по подобным особенностям в массиве квантовых точек. При $77 \mathrm{~K}$ (рис. 1, кривая 2) наблюдается участок зависимости вида $S_{I} \propto I^{3}$, согласно [19] вызванный перестройкой или генерацией дефектов. Несмотря на близкий характер организации наноматериала и геометрии активной области $\mathrm{MQW}$, значения ВКЭ в максимуме и вид зависимостей ВКЭ от тока зеленых светодиодов существенно отличались от таковых для синих светодиодов (рис. 2 и кривая 2 на вставке к рис. 2). Прежде всего это проявляется в характере нарастания излучательной рекомбинации в области малых токов инжекции и отсутствии максимума на зависимостях ВКЭ от плотности тока в светодиодах с длиной волны 519 нм (рис. 2, кривая 1) и партии II с длиной волны 530 на (кривая 2 на вставке к рис. 2), что свидетельствует об отсутствии излучательной рекомбинации локализованных носителей. При этом по геометрии MQW в зеленых светодиодах, как уже выше отмечалось, не отличается от хорошо сформированной активной области MQW синих светодиодов, имеющих отчетливо выраженный максимум ВКЭ и высокую эффективность (рис. 2, кривая 3), характерные для излучательной рекомбинации локализованных носителей. Для выяснения причин низких значений ВКЭ зеленых светодиодов при измерении зависимостей ВКЭ от плотности тока был одновременно введен дополнительный контроль значений пиковой длины волны излучения, т.е. длины волны, соответствую- 


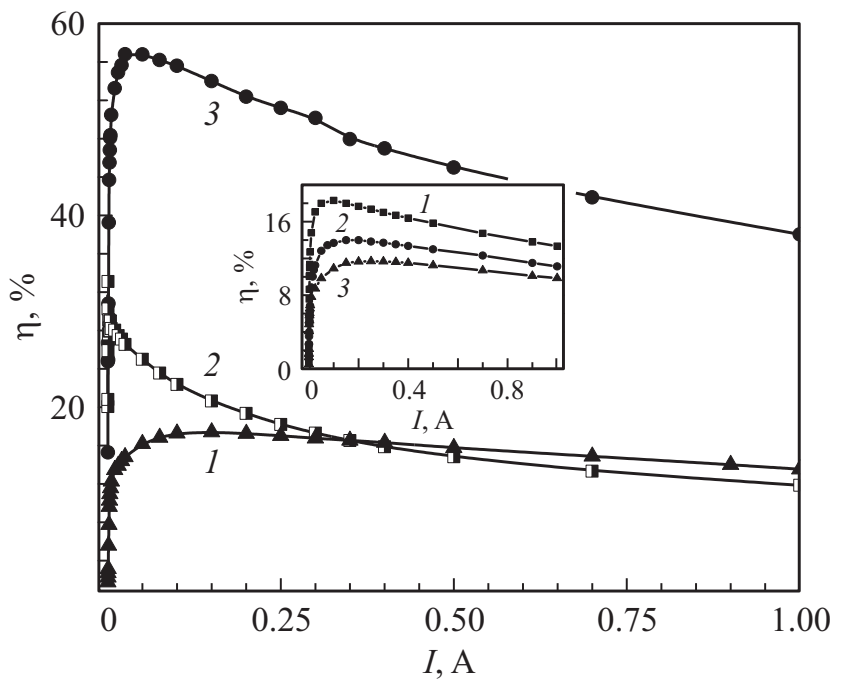

Рис. 2. Эксперименталные зависимости внешней квантовой эффективности от плотности тока светодиодов, излучающих на длинах волн 519, 530 и 460 нм: 1 - светодиоды на длину волны 519 нм, 2 - светодиоды на длину волны 530 нм (партия I), 3 - светодиоды на длину волны 454 нм. На вставке светодиоды на длину волны 530 нм (партия II) после разных этапов процесса старения: 1 - после 870 ч, 2 - исходные, 3 - после 2000 ч.

щей максимальным значениям ВКЭ при фиксированных значениях плотности тока. Сравнительный анализ одновременно полученных зависимостей ВКЭ от плотности тока (рис. 2) и распределений значений пиковой длины волны при тех же плотностях тока и на тех же светодиодах (рис. 3) позволил выявить присутствие локальных областей, обогащенных индием, с низкими значениями ВКЭ, < 2\%. Присутствие таких областей выявляется только для светодиодов с низкими значениями ВКЭ в максимуме интенсивности спектра излучения на длине волны 519 нм и светодиодов партии II на длине волны 530 нм. Как хорошо видно из рис. 3 (кривая 1), для зеленых светодиодов партии II с самой низкой эффективностью при плотностях тока $<0.1 \mathrm{~A} / \mathrm{cm}^{2}$ присутствуют локальные области с длиной волны излучения 540 нм и эффективностью $<2 \%$, что свидетельствует о нерегулярном составе твердого раствора, обогащенного индием. Очевидно, что такие области приводят не только к оптическим потерям, но и к безызлучательной рекомбинации, а также к сдвигу максимума зависимости ВКЭ от плотности тока в область больших плотностей тока. В зеленых светодиодах партии I (рис. 3, кривая 3) и в синих светодиодах (рис. 3, вставка) такие области не обнаружены при тех же условиях эксперимента. Излучение начинается практически на длине волны максимума, сдвинутой не более, чем на $1-2$ нм, и с эффективностью, близкой к максимальным значениям. Следует отметить, что получение равновесных твердых растворов на основе нитридов элементов III группы - задача более сложная, чем в системах на основе традиционных полупроводниковых материалов. Она осложнена тем, что для твердых растворов с содержанием индия, используемым в приборных структурах, критические толщины не превышают 3 нм. В результате отработка режимов роста на более толстых единичных слоях невозможна из-за распада твердого раствора, а на тонких слоях не хватает чувствительности для их эффективного контроля. При исследовании твердых растворов в квантово-размерных структурах накладываются эффекты, вызванные влиянием качества гетерограниц, количества ям и соотношения толщин ям и барьеров MQW, уровня их легирования. На этом фоне достаточно сложно охарактеризовать свойства твердого раствора. Еще один источник потерь обнаружен в зеленых светодиодах при исследовании спектров электролюминесценции при $77 \mathrm{~K}$. Выявляется полоса с максимумом при 405 нм (рис. 4) только при больших уровнях инжекции, $\sim 800 \mathrm{MA}$, что позволяет предполагать присутствие локальных областей, обедненных индием. Увеличение времени задержки до 500 мс при регистрации спектра электролюминесценции выявило заметное уширение спектра основного излучения на полувысоте, как в длинноволновую, так и в коротковолновую область, означающее присутствие задержанной электролюминесценции, возможно, вызванной процессами донорно-акцепторной рекомбинации. Выявленные источники потерь не только снижают значения ВКЭ зеленых светодиодов, но практически подавляют механизм излучательной рекомбинации локализованных носителей. Таким образом, одной из причин низких значений ВКЭ зеленых светодиодов является модификация ФПС в процессе роста, вызванная формированием локальных областей твердого раствора с нерегулярным составом, предположительно более протяженных, чем в синих светодиодах. Присутствие локальных областей с нерегулярным (неравновесным) составом в зеленых

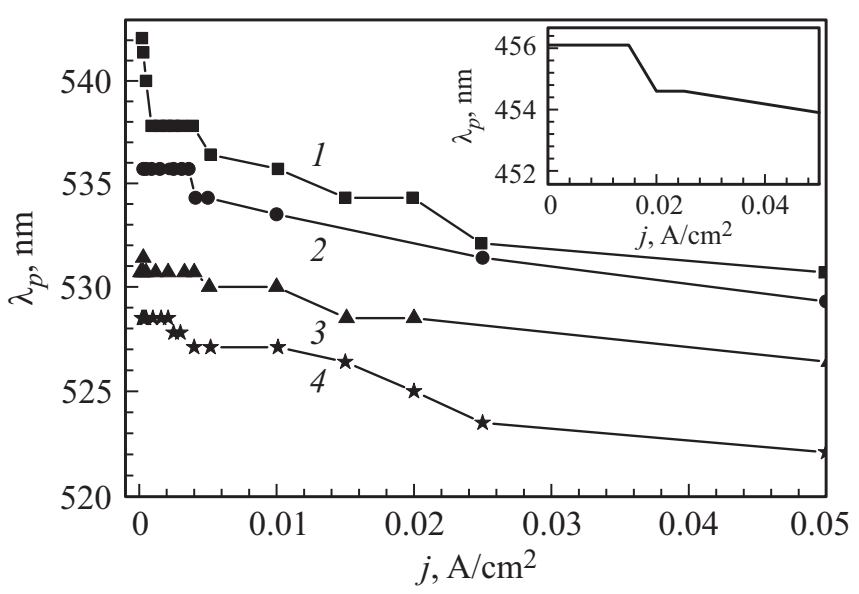

Рис. 3. Экспериментальные пиковые значения длины волны $\lambda_{p}$ при фиксированных значениях плотности тока тех же светодиодов (см. рис. 2): 1 - светодиоды на длину волны 530 нм (партия I), 2 - светодиоды на длину волны 530 нм (партия I) после 870 ч, 3 - светодиоды на длину волны 530 нм (партия II), 4 - светодиоды на длину волны 519 нм. На вставке пиковые значения длины волны при фиксированных значениях плотности тока светодиодов на длину волны 454 нм. 


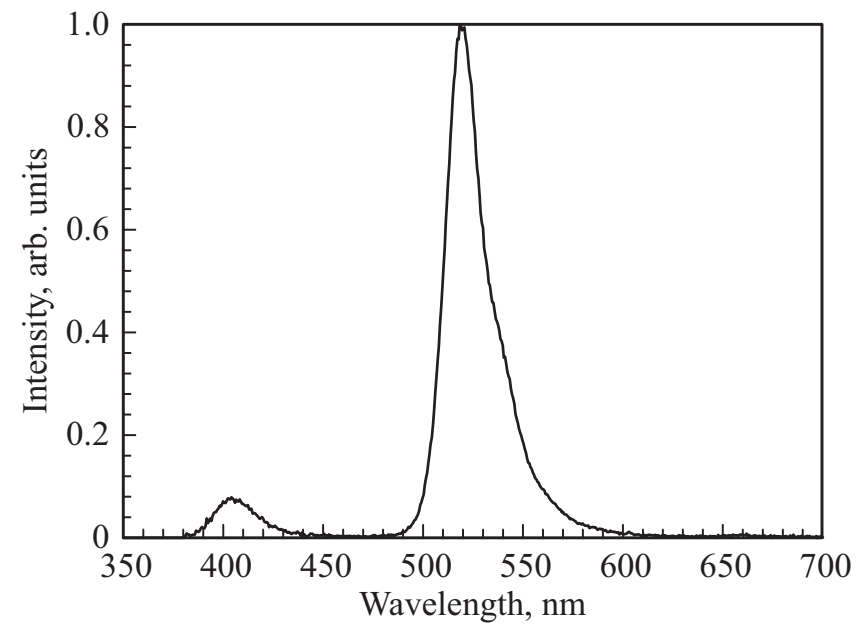

Рис. 4. Спектр электролюминесценции зеленых светодиодов, излучающих на длине волны 530 нм, при температуре $77 \mathrm{~K}$ и токе 800 мА.

светодиодах подтвердилось при их тестировании на срок службы. При временах тестирования < 1000 ч наблюдается модификация областей с повышенным содержанием индия в твердом растворе (рис. 3, кривая 2). При этом существенно уменьшается вклад таких областей в распределение пиковых значений длины волны при фиксированных значениях плотности тока, причем области с максимальным содержанием индия не высвечиваются. Заметно растут значения ВКЭ в максимуме (кривая 1 на вставке к рис. 2) по сравнению с исходными значениями (кривая 2 на вставке к рис. 2), причем, появляется вклад излучательной рекомбинации локализованных носителей, что следует из характера нарастания зависимости ВКЭ от плотности тока (кривая 1 на вставке к рис. 2). При этом сильных изменений проводимости ФПС и искажений прямой ветви ВАХ не наблюдается, т.е. происходит модификация только локальных областей неравновесного состава. Увеличение времени тестирования до 2000 ч и более приводит к эффектам (кривая 3 на вставке к рис. 2), ранее наблюдавшимся в синих светодиодах [20] - сильному изменению проводимости ФПС, искажению прямой ветви ВАХ при малых смещениях, сдвигу максимума ВКЭ в сторону больших токов, снижению эффективности в максимуме и к отсутствию вклада излучательной рекомбинации локализованных носителей в ВКЭ.

\section{2. Изменение характеристик}

AIGaN/GaN-HEMT при модификации
свойств фрактально-перколяционной
системы в процессе роста и при
взаимодействии с потоком протонов
с энергией 1 МэB, дозами от $5 \cdot 1^{13}$
до $2 \cdot 1^{14}$ см $^{-2}$

Исследования проводились на двух типах НЕМТструктур, существенно различавшихся только по характеру организации наноматериала, т. е. по свойствам ФПС, охарактеризованным значениями $\Delta_{p}=0.345$, $0.350,0.357$, а также на транзисторах, изготовленных из этих структур. До облучения на части приборных структур проводились измерения подвижности носителей заряда в двумерном канале при 77 и $300 \mathrm{~K}$, а на транзисторах выходные характеристики и токи затворов. При этом для НЕМТ с разным характером организации наноматериала наблюдался разброс значений подвижности, но лучшие значения были существенно выше для HEMT с меньшим значением параметра $\Delta_{p}$. Так, для HЕМТ с $\Delta_{p}=0.345$ значения подвижности составляли при комнатной температуре $1598-1647 \mathrm{~cm}^{2} \cdot \mathrm{B}^{-1} \cdot \mathrm{c}^{-1}$, при $\quad 77 \mathrm{~K} \quad 12150-7073 \mathrm{~cm}^{2} \cdot \mathrm{B}^{-1} \cdot \mathrm{c}^{-1}$, для НЕМТ c $\Delta_{p}=0.350$ значения подвижности при комнатной температуре $913-1144 \mathrm{~cm}^{2} \cdot \mathrm{B}^{-1} \cdot \mathrm{c}^{-1}, \quad$ при $\quad 77 \mathrm{~K}$ $4170-5820 \mathrm{~cm}^{2} \cdot \mathrm{B}^{-1} \cdot \mathrm{c}^{-1}$, а для НЕМТ с $\Delta_{p}=0.357$ наблюдаются не только более низкие значения подвижности носителей заряда, но и существенная разница значений подвижности электронов по разным парам контактов при одинаковом их контактном сопротивлении. Часть результатов по исследованию температурных зависимостей подвижности была представлена в [15]. Контроль тока затворов транзисторов показал, что при смещениях > 1 В BAX НЕМТ-структур с разным характером организации достаточно единообразны (рис. 5), в то время как при меньших смещениях наблюдается большой разброс значений тока этих транзисторов, причем характер организации приборной структуры значительно влияет как на минимальные значения тока затвора, так и на разброс этих значений. На вставке к рис. 5 приведены лучшие прямые ветви ВАХ затворов транзисторов, полученные из структур с разными значениями $\Delta_{p}$ при смещениях $<1 \mathrm{~B}$. С ростом значения $\Delta_{p}$ наблюдается рост тока затвора до трех порядков относи-

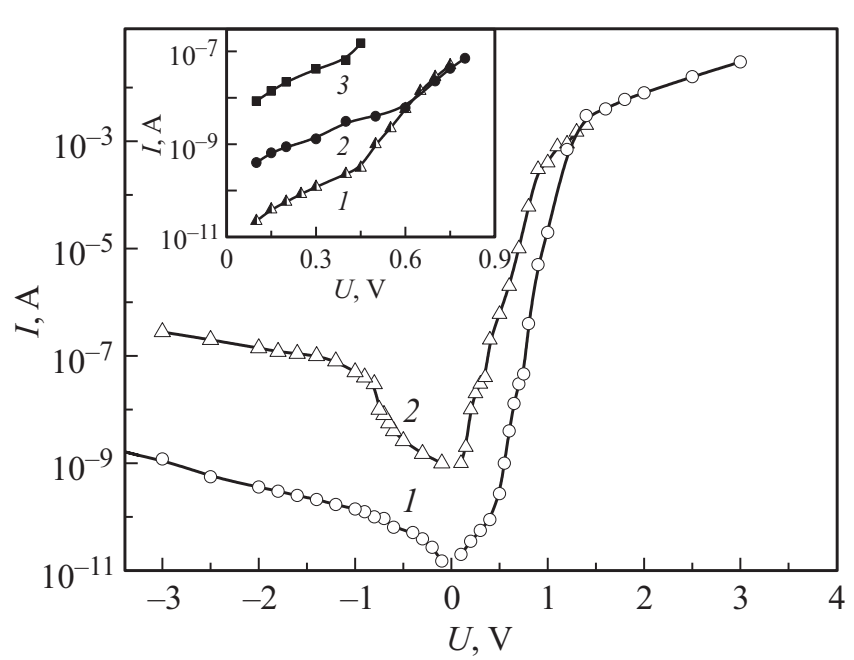

Рис. 5. Вольт-амперные характеристики затвора $\mathrm{AlGaN} / \mathrm{GaN}$ НЕМТ с разной степенью упорядоченности: $\Delta_{p}=0.345$ (1), 0.350 (2). На вставке - прямые ветви ВАХ при малых смещениях НЕMT с $\Delta_{p}=0.345$ (1), 0.350 (2), 0.357 (3). 
тельно токов, полученных на транзисторах, собранных из структур с более высокой упорядоченностью. Для транзисторов из таких пластин разброс значений тока затвора относительно минимальных для 75\% транзисторов существенно меньше порядка, для остальных 25\% достигает порядка. Значительно больший разброс значений тока затвора, до двух порядков, наблюдается на $60 \%$ транзисторов, полученных из структур с $\Delta_{p}=0.357$. Изменение прямой и обратной ветвей $\mathrm{BAX}$ затворов с ростом $\Delta_{p}$, выявляющее рост проводимости шунтов и значения коэффициентом идеальности $n>2$ при смещениях $<1 \mathrm{~B}$, позволяет предполагать, что наблюдаемый разброс значений тока вызван изменением свойств ФПС. Оценки надежности исследованных транзисторов выявили связь этого параметра со значениями $\Delta_{p}$, но не прямую корреляцию, так как очевидно, что это не единственный параметр, влияющий на надежность. Для оценки надежности параметров НЕМТ-структур был использован стандартный метод контроля [21] по изменению тока затвора после приложения смещения -50 В в течение 250 ч. На транзисторах, полученных из структур с $\Delta_{p}=0.357$, рост тока затвора более чем на порядок и падение выходной мощности наблюдаются через несколько минут, а на части транзисторов, без применения теста, после повторных включений. На транзисторах, полученных из структур с более высокой организацией наноматериала $\left(\Delta_{p}=0.345\right)$, падение выходной мощности наблюдается через сотни часов, причем при повышенных температурах, $\sim 300^{\circ} \mathrm{C}$. Изучение зависимостей флуктуаций напряжения $\left(S_{v}\right)$ на затворе от тока на низкой частоте, 1.22 Гц, выявило, в том числе и на транзисторах с малыми значениями токов, неоднородное распределение тока по площади затвора как при $300 \mathrm{~K}$, так и при $77 \mathrm{~K}$ (рис. 6). Неоднородность протекания тока была идентифицирована по отклонению зависимостей $S_{v}(I)$ от вида $S_{v} \propto I^{-1}$, типичного, согласно теории [22], для барьеров Шоттки и $p-n$-переходов с однородным распределением тока. Кроме того, уровень шума затвора транзисторов при $77 \mathrm{~K}$ выше, чем при $300 \mathrm{~K}$ (рис. 6, кривая 1), несмотря на то что подвижность носителей заряда при $77 \mathrm{~K}$ в несколько раз выше. Механизм, приводящий к наблюдаемому явлению, не выяснен. Подобное явление наблюдалось в [23] на AlGaAs/GaAs-HEMT и интерпретировалось как результат туннелирования носителей в твердый раствор. Ранее было показано, что неоднородность протекания тока выявляется на излучающих приборах на основе нитридов элементов III группы [7] и связана со свойствами ФПС.

Взаимодействие протонов с НЕМТ-структурами $\mathrm{AlGaN} / \mathrm{GaN}$ с разной упорядоченностью наноматериала и транзисторами, сформированными из этих структур, при малых дозах облучения, $5 \cdot 10^{13} \mathrm{~cm}^{-2}$, не вызывает существенного изменения характеристик транзисторов, полученных из структур с $\Delta_{p}=0.345$; для структур с меньшей упорядоченностью наблюдается улучшение характеристик на части транзисторов, но при этом

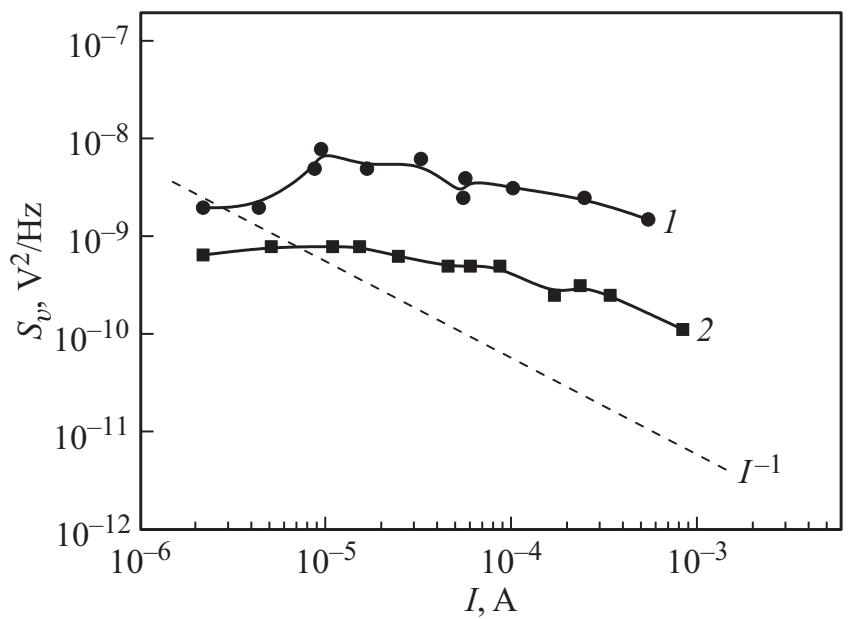

Рис. 6. Зависимости плотности флуктуаций напряжения от тока в HEMT-структурах AlGaN/GaN при 77 (1) и $300 \mathrm{~K}$ (2).

уровень токов не достигает значений, представленных на вставке к рис. 5 (кривая 1), характерных для транзисторов с высокой упорядоченностью, но приближается к значениям, соответствующим приведенным на кривой 2. При дозе $1 \cdot 10^{14} \mathrm{~cm}^{-2}$ для структур с наименьшей упорядоченностью измерения температурной зависимости подвижности на разных участках транзисторной структуры выявили падение подвижности в 4-5 раз, а на отдельных участках канал не работал. Часть результатов по исследованию температурных зависимостей подвижности транзисторных структур была представлена в [24]. Кроме того, наблюдалось возникновение разупорядоченных локальных областей наноматериала, с нарушением и уширением ростовых ступеней, выявленное методами атомно-силовой микроскопии. Значения параметра упорядоченности на этих структурах выросли до $\Delta_{p}=0.365$, выросли проводимость и токи затвора, а кроме того, до $60 \%$ транзисторов перестали функционировать, что коррелирует с вышеприведенными данными по разбросу токов затвора, превышающих порядок и более относительно минимальных значений при смещении $<1$ В до облучения. На НЕМТ-структурах с $\Delta_{p}=0.345$ существенные изменения упорядоченности, подвижности носителей заряда и токов затвора наблюдаются после воздействия протонов с дозой $2 \cdot 10^{14} \mathrm{~cm}^{-2}$. На рис. 7 представлены АСМ-изображения поверхностей типичных участков НЕМТ-структуры с $\Delta_{p}=0.345$ до и после облучения протонами. Появление менее упорядоченных областей наблюдается практически на всей поверхности НЕМТструктуры, но характер различен на разных участках. Количественные оценки параметра $\Delta_{p}$ на разных участках этой структуры дают значения от 0.350 до 0.365 , в то время как до облучения протонами эти значения и их разброс на разных участках были заметно меньше: 0.345-0.348. Эти результаты коррелируют с данными по шероховатости поверхности. Значения параметра 


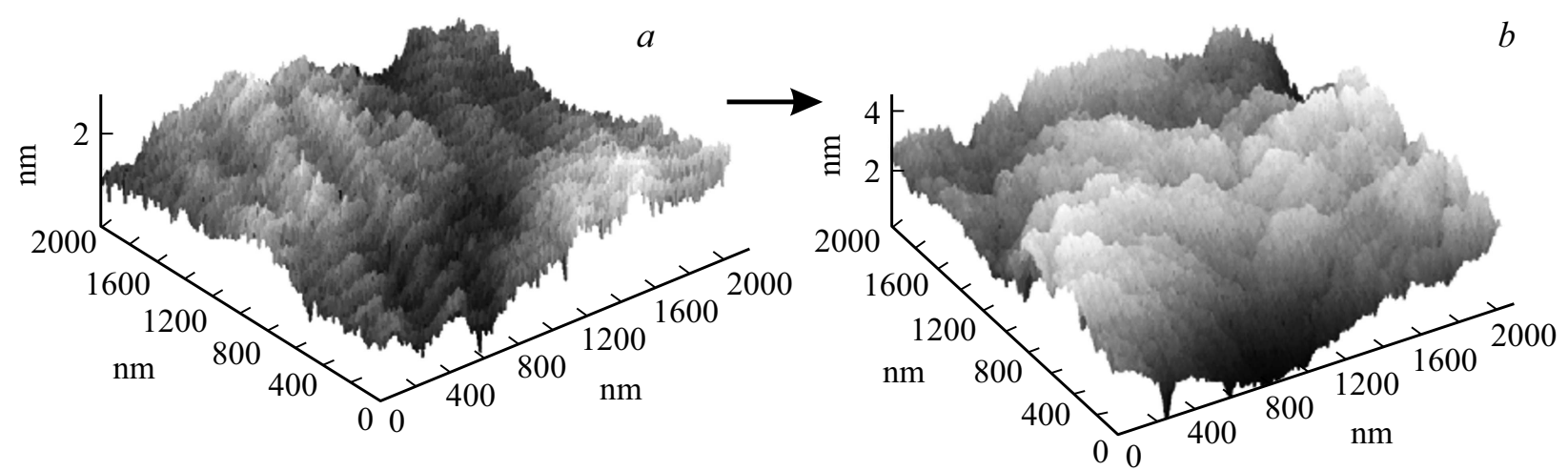

Рис. 7. Эволюция поверхности НЕМТ-структур $\mathrm{AlGaN} / \mathrm{GaN}$ под воздействием протонов с энергией 1 мэВ и дозой $2 \cdot 10^{-14} \mathrm{~cm}^{-2}$ : вид поверхности в атомно-силовом микроскопе до $(a)$ и после облучения $(b)$.

RMS в поле размером $2 \times 2$ мкм на разных участках структуры составляют $0.2320-0.3375$ нм до облучения, возрастают до $0.5115-0.8170$ нм после облучения и отражают значительное увеличение разброса между участками одной и той же структуры. Параметр $P_{p}$, регистрирующий максимальную разницу по высоте рельефа в отдельных точках исследуемых участков, дает разброс 2.262-2.654 нм до воздействия и 8-25 нм после воздействия. Кроме того, на транзисторах наблюдается падение тока сток-исток до $20 \%$ и рост минимальных токов затворов до порядка. Часть транзисторов, до $40 \%$, перестает функционировать, что коррелирует с вышеприведенными в этой статье данными по разбросу значений тока затвора, превышающих порядок и более относительно минимальных значений при смещении $<1$ В до облучения. Полученные результаты позволяют предполагать, что интенсивное дефектообразование происходит прежде всего в локальных областях ФПС, так как наблюдаются существенные изменения проводимости транзисторов и искажений прямой ветви при смещениях $<1 \mathrm{~B}$ и они усиливаются, причем локально, при меньшей упорядоченности до облучения. Дефектообразование может происходить в локальных областях ФПС в результате взаимодействия возбужденной электронной подсистемы с фононами. Очевидно, что для обсуждения механизмов дефектообразования и количественных оценок необходимы дополнительные исследования. Полученные результаты на транзисторах с $\Delta_{p}=0.345$ по радиационной стойкости соответствуют лучшим опубликованным [25].

\section{4. Заключение}

Выяснено, что модификация ФПС в процессе роста зеленых светодиодов может приводить к формированию локальных областей твердого раствора с нерегулярным составом, обогащенных индием, с ВКЭ ниже $2 \%$, предположительно более протяженных, чем в синих светодиодах. Эти области подавляют излучательную рекомбинацию локализованных носителей, являются источником потерь на безызлучательную рекомбинацию и одной из причин низких значений эффективности зеленых светодиодов и разброса значений эффективности светодиодов разных фирм в несколько раз. Показано, что свойства ФПС в НЕМТ-структурах проявляются так же, как в светодиодах, - в особенностях ВАХ затворов при смещениях $<1 \mathrm{~B}$, таких как величина проводимости шунтов и искажения прямой ветви ВАХ с ростом фактора идеальности $>2$. Модификация этих свойств в широких пределах наблюдается при изменении характера организации наноматериала на стадии роста, под действием облучения протонами с энергией $1 \mathrm{MэB} \mathrm{и} \mathrm{приводит}$ к разбросу значений подвижности носителей заряда в двумерном канале в пределах порядка при $77 \mathrm{~K}$, проводимости шунтирующих каналов до нескольких порядков и низкой надежности транзисторов. Улучшение характера организации наноматериала позволяет существенно, до 1.5 раз, снизить разброс значений подвижности носителей заряда, проводимость шунтирующих каналов на порядки, разброс значений проводимости до нескольких раз и повысить надежность транзисторов. Полученные результаты показали значительное влияние локальной разупорядоченности наноматериала, как присутствующей в HЕMT-структурах $\mathrm{AlGaN} / \mathrm{GaN}$ до облучения, так и усиливающейся после воздействия протонов, на параметры транзисторов и их радиационную стойкость. Кроме того, полученные результаты проливают свет на имеющиеся в литературе данные разных авторов по расхождению пороговых значений радиационной стойкости и надежности транзисторов на основе НЕМТструктур $\mathrm{AlGaN} / \mathrm{GaN}$. Эти результаты показывают, что повышение упорядоченности наноматериала и ее контроль в процессе производства транзисторов могут стать одним из способов повышения радиационной стойкости и надежности НЕМТ-транзисторов. Результаты по модификации свойств ФПС потоком протонов еще раз подтвердили важный вклад ФПС в параметры приборных структур.

Работа выполнена при поддержке РФФИ (грант № 17-08-01000 A). 


\section{Список литературы}

[1] C.A. Hurni, A. David, M.J. Cich, R.I. Aldaz, B. Ellis, K. Huang, M.R. Krames. Appl. Phys. Lett., 106, 031101 (2015).

[2] F. Nippert, S.Yu. Karpov, G. Callsen, B. Galler, T. Kure, C. Nenstiel, M.R. Wagner, M. Strassburg, H.-Ju. Lugauer, Axel Hoffmann. Appl. Phys. Lett., 109, 1611039 (2016).

[3] M. Auf der Maur, A. Pecchia, G. Penazzi, W. Rodrigues, A. Di Carlo. Phys. Rev. Lett., 116, 027401 (2016).

[4] P. Marko, M. Menegini, S. Bychikhin, G. Meneghesso, D. Pogany. Microelectron. Reliab., 52, 2194 (2012).

[5] R. Lossy, H. Blanck, J. Wurfl. Microelectron. Reliab., 52, 2144 (2012).

[6] G. Pozina, R. Ciechonski, Zh. Bi, L. Samuelson, B. Monemar. Appl. Phys. Lett., 107, 251106 (2015).

[7] В.Н. Петров, В.Г. Сидоров, Н.А. Тальнишних, А.Е. Черняков, Е.И. Шабунина, Н.М. Шмидт, А.С. Усиков, Н. Helava, Ю.Н. Макаров. ФТП, 50 (9), 1173 (2016).

[8] M. Binder, B. Galler, M. Furitsch, J. Off, J. Wagner, R. Zeisel, S. Katz. Appl. Phys. Lett., 103, 221110 (2013).

[9] M. Auf der Maur, B. Galler, I. Pietzonka, M. Strassburg, H. Lugauer, A. Di Carlo. Appl. Phys. Lett., 105, 133504 (2014).

[10] Н.И. Бочкарева, А.М. Иванов, А.В. Клочков, В.С. Коготков, Ю.Т. Ребане, М.В. Вирко, Ю.Г. Шретер. ФТП, 49 (6), 847 (2015).

[11] C. De Santi, M. Meneghini, M. La Grassa, B. Galler, R. Zeisel, M. Goano, S. Dominici, M. Mandurrino, F.Bertazzi, D. Robidas, G. Meneghesso, E. Zanoni. J. Appl. Phys., 119, 094501 (2016).

[12] S. Steingrube, O. Breitenstein, K. Ramspeck, S. Glunz, A. Schenk, P.P. Altermatt. J. Appl. Phys., 110, 014515 (2011).

[13] N. Shmidt, A. Usikov. E. Shabunina, A. Chernyakov, A. Sakharov, S. Kurin, A. Antipov, I. Barash, A. Roenkov, H. Helava, Y. Makarov. Physica Status Solidi C, 12 (4-5), 349 (2015).

[14] Н.М. Шмидт, А.С. Усиков, Е.И. Шабунина, А.Е. Черняков, А.В. Сахаров, С.Ю. Курин, А.А. Антипов, И.С. Бараш, А.Д. Роенков, Ю.Н. Макаров, Н. Helava. Письма ЖТФ, 40 (13), 73 (2014).

[15] В.В. Емцев, Е.Е. Заварин, Г.А. Оганесян, В.Н. Петров, А.В. Сахаров, Н.М. Шмидт, В.Н. Вьюгинов, А.А. Зыбин, Я.М. Парнес, С.И. Видякин, А.Г. Гудков, А.Е. Черняков. Письма ЖТФ, 42 (13), 80 (2016).

[16] V.A. Shalygin, L.E. Vorobjev., D.A. Firsov, A.N. Sofronov, G.A. Melentyev, W.V. Lundin, A.V. Sakharov, A.F. Tsatsulnikov. J. Appl. Phys., 109, 073108 (2011).

[17] A.E. Chernyakov, M.E. Levinshtein, N.A. Talnishnikh, E.I. Shabunina, N.M. Shmidt. J. Cryst. Growth, 401, 302 (2014).

[18] L. Dobrzanski. J. Appl. Phys., 96, 4135 (2004).

[19] Г.П. Жигальский. Флуктации и шумы в электронных твердотельных приборах (М., Физматлит, 2012) с. 512.

[20] А.Л. Закгейм, М.Е. Левинштейн, В.П. Петров, А.Е. Черняков, Е.И. Шабунина, Н.М. Шмидт. ФТП, 46 (2). 219 (2012).

[21] B. Lambert, N. Labat, D. Carisetti, L. Brunel, M. Mermoux. Microelectron. Reliab., 52, 2184 (2012).

[22] Н.В. Дьяконова, M.Е. Левинштейн, S. Contreras, W. Knap, В. Beaumont, P. Gibart. ФТП, 32 (3), 285 (1998).

[23] S.L. Rumyantsev, Y. Deng, E. Borovitskaya, A. Dmitriev, W. Knap, N. Pala, M.S. Shur, M.E. Levinshtein, M. Asif Khan, G. Simin, J. Yang, X. Hu. J. Appl. Phys., 92, 4726 (2002).
[24] В.В. Емцев, Е.Е. Заварин, М.А. Козловский, М.Ф. Кудояров, В.В. Лундин, Г.А. Оганесян, В.Н. Петров, Д.С. Полоскин, А.В. Сахаров, С.И. Трошков, Н.М. Шмидт, В.Н. Вьюгинов, А.А. Зыбин, Я.М. Парнес, С.И. Видякин, А.Г. Гудков, А.Е. Черняков, В.В. Козловский. Письма ЖТФ, $42(21), 39$ (2016).

[25] Д.В. Громов, Г.В. Чуков. Влияние радиачии на гетероструктурные СВЧ приборы и интегральные схемы (Palamarium Academic Publishing, 2012) c. 91.

Редактор Л.В. Шаронова

\section{The diversity of properties of device structures based on III-nitrides, related to modification of the fractal-percolation system}

\author{
V.V. Emtsev ${ }^{\mathbf{1}}$, E. Gushina ${ }^{\mathbf{1}}$, V.N. Petrov ${ }^{\mathbf{1}}$, \\ N.A. Tal'nishnih ${ }^{2}$, A.E. Chernyakov' ${ }^{2}$, \\ E.I. Shabunina ${ }^{1}$, N.M. Shmidt ${ }^{1}$, A.S. Usikov ${ }^{3}$, \\ A.P. Kartashova ${ }^{1}$, A.A. Zybin ${ }^{4}$, V.V. Kozlovski ${ }^{5}$, \\ M.F. Kudoyarov' ${ }^{1}$, A.V. Saharov' ${ }^{1}$, G.A. Oganesyan ${ }^{1}$, \\ D.S. Poloskin ${ }^{1}$, V.V. Lundin ${ }^{1}$ \\ ${ }^{1}$ loffe Institute, \\ 194021 St. Petersburg, Russia \\ ${ }^{2}$ Submicron Heterostructures for Microelectronics \\ Research and Engineering Center, \\ Russian Acasemy of Sciences, \\ 194021 St. Petersburg, Russia \\ ${ }^{3}$ Nitride Crystals Inc., $181 \mathrm{E}$ Industry Ct., \\ Ste. B, Deer Park, \\ NY 11729, USA \\ ${ }^{4}$ JSC "Svetlana-Electronpribor", \\ 194156 St. Petersburg, Russia \\ ${ }^{5}$ Peter the Great Saint-Petersburg \\ Polytechnic University, \\ 195251 St. Petersburg, Russia
}

\begin{abstract}
The fractal-percolation system which includes extended defects as well as random fluctuations in the alloy composition is generated during the growth of device structures based on III-nitrides. It is shown that the peculiarities of this system are not defined by the growth conditions only. The diversity of electrical and optical characteristics of $\mathrm{InGaN} / \mathrm{GaN}$ LEDs emitting at the $450-460$ and $519-530 \mathrm{~nm}$ wavelengths as well as electrophysical properties of $\mathrm{AlGaN} / \mathrm{GaN}$ HEMT structures is found to be caused by modification of the fractal-percolation system properties during the growth process as well as under the injection current and irradiation. The influence of these peculiarities on the operational time of light-emitting devices and reliability of $\mathrm{AlGaN} / \mathrm{GaN}$ HEMT structures are discussed.
\end{abstract}

